\title{
Risks and Complications Associated with Orthodontic Treatment
}

\author{
Cristina Teodora Preoteasa, Ecaterina Ionescu and Elena Preoteasa \\ Faculty of Dental Medicine, "Carol Davila" \\ University of Medicine and Pharmacy, Bucharest
}

Romania

\section{Introduction}

Orthodontic treatment of malocclusions and craniofacial abnormalities, by ensuring proper alignment of the teeth, harmonious occlusal and jaw relationship, may improve mastication, phonation, facial aesthetics, with beneficial effects on the general and oral health, individual's comfort and self-esteem, having a positive role in improving the quality of life. Therefore, the treatment's objectives are consistent with the aims of medical interventions, namely ensuring health, the "state of complete physical, mental and social well-being", as perceived by the World Health Organization (World Health Organization, 1946).

Like any other medical intervention, orthodontic treatment has, in addition to its benefits, also associated risks and complications. In orthodontics, the risk of "doing harm" is considerably lower compared to other medical interventions, e.g., the surgical ones. However, during the medical act, through usage of various procedures, devices and materials, there might appear unwanted side effects, both local (tooth discolorations, decalcification, root resorption, periodontal complications) and systemic (allergic reactions, chronic fatigue syndrome).

An increased risk of complications may contraindicate the orthodontic therapy or influence its objectives, phases and conduct, aspects directly linked with the quality of the final outcome and prognosis. Generally speaking, the consecutive benefits of the medical intervention must overcome any potential damage. Legal regulations on medical conduct emphases the patient's right, as participant in treatment decision making, to be informed about the benefits and possible risks that might occur. It is recommended to make for each patient a rigorous risk profile analysis, followed by obtaining a signed informed consent. In case side effects appear, the avoidance of informing the patients about possible complications associated with the medical act may lead to malpractice complaints or even lawsuits.

This chapter aims to highlight the main coordinates of risk issues in orthodontics. In this respect, it starts with an analysis of the context in which they occur, followed by a presentation of the main complication linked to orthodontic intervention, and concludes with a general approach of the topic from the perspective of risks management principles 
The following information represents a literature review, in the context of the current state of knowledge, combined with data from authors' personal observations and research.

\section{Context of the side effects appearance during orthodontic treatment}

Side effects associated with orthodontic treatment occur within the interaction between factors related to the patient, medical team and orthodontic technique. These can be perceived as elements belonging to the general therapeutic context, present when medical interventions are delivered, and aspects related to a specific therapeutic context, namely linked to the orthodontic intervention (Table 1). Local and systemic side effects may occur to patients (those receiving the intervention), but also to the medical team members (those managing the intervention, handling various materials and instruments).

\section{CONTEXT OF RISK OCCURRENCE DURING ORTHODONTIC TREATMENT}

General therapeutic context

- patient's features

- orthodontist related factors

- doctor-patient relationship

Specific therapeutic context

- $\quad$ related to the placement of orthodontic devices

- related to the action mechanism of the orthodontic appliances

- related to the relation of the orthodontic appliance with the oral structures

- related to material properties and technical particularities of the orthodontic appliances

Table 1. Main coordinates of risk occurrence during orthodontic interventions.

\subsection{General therapeutic context}

During orthodontic therapy complications may be linked to the general context present when medical interventions are delivered, may be appeared in relation to specific patient features, linked to the medical staff responsible for delivering the intervention or associated to a deficient patient-doctor relationship.

There are many variables related to the patient that can influence the risk occurrence during orthodontic therapy. Among these are individual characteristics related to age, gender, environment, physiopathological status, genetic predisposition, psychological type, as well as particularities related to malocclusion (type, etiology, severity) and craniofacial features. In order to reduce the frequency and severity of the complications associated with this type of medical intervention, it is necessary to know the detailed particularities of each case, which need to be integrated within the treatment plan and conduct of the medical care. For example, within various age groups there are specific aspects of the physiopathological status, development and cooperation, which can influence the timing for orthodontic therapy, treatments' objectives, appliances choice, duration of treatment and stability of the outcome. Within young age patients considered appropriate to receive orthodontic intervention, there are mainly those with functional imbalances, anterior or posterior crossbite and those with severe narrow upper dental arch. But there are procedures (like expansion of the lower arch to resolve dental crowding) implemented in the mixed dentition 
that are sometimes unstable. Therefore, the orthodontic treatment is often instituted into the late mixed dentition, just before loss of the deciduous mandibular second molar, with the benefits of a better collaboration with the patient, the possibility of using the leeway space and influencing the jaw bone growth, with shortening as much as possible the duration of active treatment (DiBiase, 2002). The treatment of the adult patient often requires particularization of the orthodontic intervention due to oral structures changes and modified physiopathological status. More frequently periodontal alterations are present (reduction of the alveolar bone support with the modification of the tooth's rotation center, favoring a faster tooth movement; increased bone density associated with a slower tooth movement), also a higher intensity and duration of pain and increased prevalence of devital teeth (with an uncertain behavior during tooth movement) (Shah \& Sandler, 2006). Modified health status may increase the appearance risk of certain complication or interfere with the orthodontic treatment conduct. For example, in case of bisphosphonates usage, among the side effects, the orthodontist should be concerned about the difficulties of achieving a desired tooth movement (long-lasting aspect after drug discontinuation) and also about the slower bone healing rate with the possibility of osteonecrosis appearance (especially important when tooth extractions, implant placement or phases of orthognathic surgery are planned) (Iglesias-Linares et al., 2010).

A good progress of the orthodontic treatment is related also to the patient's understanding and compliance regarding the physician's indications, which aims mainly the oral hygiene and device maintenance, and rigorousity in attending the periodical appointments. Failure to comply with these conditions may result in damaging the components of the orthodontic appliances, damage of the oral structures (risk factor for demineralizations, caries, discolorations, periodontal damage, bad breath), increased duration of the treatment and not achieving the expected result.

The orthodontist has an important role in preventing the complications associated with this type of treatment, being the manager and implementer of the medical intervention delivered. In order to obtain good results and minimize the complications aspects like an appropriate training, knowledge, clinical skills and experience are needed. Being a distinctive specialty within dentistry, orthodontic training has in many countries a particular education system. Usually a 2 to 3 year period of postgraduate study for qualification in this field is done. Over the last decade, there was also observed in this specialty an increased interest for the concept of evidence-based orthodontics. The orthodontist's challenge in the XXI century is to integrate the best scientific evidence into practice, this representing the "gold" standard of the medical care quality, from the perspective of the current state of knowledge (Ackerman, 2004). Also, in order to achieve a high standard of treatment quality, with minimal complication, it is necessary for the orthodontist to have all the necessary means for implementing the optimal considered treatment. For example, in order to include an orthognathic surgical phase it is necessary for the orthodontist to have a professional collaboration with a maxillofacial surgeon, preferably with his practice as close as possible, for an easy patient's access. Generally we can say that complications that occur due to errors of diagnosis, treatment planning or treatment management related to orthodontist's intervention can be avoided through practitioner's appropriate training, good theoretical knowledge and clinical skills and also 
possession of all necessary elements for implementation of the treatment plan considered optimal.

The doctor-patient relationship is another important key factor in ensuring a high quality medical act, having either positive or negative impact on treatment conduct. When an orthodontic treatment begins the physician, patient and person with the legal authority for minors become a team with a common goal: insuring the health status for identified problems. Communication is a key element in achieving quality results, but difficulties may arise for various reasons like a child patient, a person with disabilities or lack of interest towards the medical aspects. Generally, the most common difficulties are related to the understanding of the medical aspects by the patient, and complementary, the doctor's ability to make himself understood. When the physician is using a specialized medical language, the patient may feel inferior and may avoid requesting additional data, limiting the possibilities of using the received information. In this regard, it is recommended the clear presentation of the medical information to the patient, in a clear language, avoiding the usage of specialized terminology. Frequently, the orthodontically treated patients are children, the cooperation and communication being in general more difficult in younger ages. In their case, the orthodontic appliance is often accepted consecutive to parents' wishes not as a result of a perceived need, unlike adult patients who are usually more motivated. The parents are generally more aware of the orthodontic treatment's necessity and have a more positive attitude than children, but studies show that the doctor-patient relationship is influenced to a small extent by the parents' attitude (Daniels et al., 2009). In order to ensure an optimal treatment conduct it is recommended to evaluate patient's and family's attitude towards the orthodontic intervention before starting the treatment. When dealing with a negative, reticent patient, sometimes it's wise to postpone the treatment, because difficulties in treatment's progression and negative health or even psychological consequences may appear.

\subsection{Specific therapeutic context}

Part of the complications observed during or after orthodontic treatment can be linked to some specific features of this type of medical intervention. These are mainly related to the placement of orthodontic appliances, to their action mechanism, to the relation of the orthodontic device with the oral structures and linked to material properties and technical particularities of the orthodontic appliances.

Orthodontic devices can be fixed, consisting of elements bonded for the entire period of active treatment (brackets, bands) or removable, being present 2 variants (element removal can be done only by orthodontist - e.g., arch-wire, or also by patient - e.g., removable appliance), with different clinical indications, advantages and disadvantages regarding cleaning, microbial loading, patient's compliance etc. Some components are active, others passive, they can detach or break, causing local or general complications. The orthodontic appliances, fixed or removable, are placed in the oral environment, in relation with the anatomical structures and interfering with dento-maxillary apparatus' functions, being usually used for a long period of time. There is a wide range of materials used for orthodontic devices fabrication and usage (e.g., metal - nickel and titanium-based components, acrylics, cements, composites resins, ceramics, latex), which present different biomechanical characteristics and structure than the oral ones. The components of the 
orthodontic devices come into contact with the oral tissues and fluids, being submitted to some complex conditions: immersion in saliva and ingested fluids, temperature fluctuations, mechanical loading during chewing and activation of the devices, physical or chemical interactions. Therefore the orthodontic appliances must not contain compounds that may cause a toxic response, not cause allergic reaction or have carcinogenic potential, must be resistant to electrochemical corrosion, should not promote the microbial adherence and development, in general - should present an optimal biocompatibility (Atai \& Atai, 2007; Bentahar et al., 2005). In this context, it is recommended to use orthodontic devices with lower nickel content, with a good resistance to corrosion and, in order to avoid corrosion of titanium based components, to limit the use of high concentration fluor-based products (Chaturvedi \& Upadhayay, 2010). For an optimal treatment conduct the materials must be resistant to forces that are applied during their usage period, should not fracture and should be suitable for processing in any configuration and shape demanded by their clinical application.

In orthodontics treatment outcome is achieved mainly through orthodontic forces action, delivered against teeth muscles and bones, having as result teeth movement, modification of bone morphology or growth. According to patient's particularities treatments must be individualized, for example orthodontic forces should be dosed in relation to aspects like patient's age and oral structure's health status (e.g. increased force magnitude can be a risk factor for root resorption, ankylosis, pulpal and periodontal damage, pain).

The orthodontic appliances, depending on their type, have a direct contact with various structure of oral cavity like teeth, muco-osseus areas of the palate and alveolar bone, tongue, cheeks, gingiva etc. Sometimes an indirect effect of their placement is present, e.g., temporomandibular joint dysfunction and muscles disorders. Various side effects are linked to the orthodontic device presence, due to modifications in oral structure configuration, special measurements of hygiene requirements, attitudes needed for protection of the soft tissues and ensuring good functionality (for example harmless occlusal contacts). Applying the fixed orthodontic devices is associated with possible irreversible enamel changes, difficulties in oral hygiene maintenance due to decreased self-cleaning and multiple new areas for plaque retention, root resorption presence, discomfort and pain.

\section{Classification of risks and complications of orthodontic treatment}

During orthodontic treatment management two aspects must be carefully considered, namely the present risks and possible complications. Between these two there is a strong connection, acknowledging them being one of the keys of delivering a safe medical care. A classification, starting from the one presented by Graber (Graber et al., 2004), is the following:

1. based on the condition's localization

- local effects, with manifestation on dento-maxillary apparatus structures (enamel demineralizations and discolorations, root resorption, gingivitis);

- $\quad$ systemic effects (allergic reactions to nickel or latex).

2. according to the condition's severity:

- $\quad$ mild, reversible (gingivitis);

- moderate, reversible (fracture of a ceramic crown); 
- $\quad$ moderate, irreversible (enamel fracture during debonding);

- $\quad$ severe, irreversible (multiples caries and decalcifications, severe root resorption).

3. based on orthodontist's role in the side effect's occurrence:

- standard inherent complications, being included side effects where the orthodontist's role is irrelevant (enamel changes due to acid etching when resins are used as bonding material);

- complications related to the patient's particularities (individual susceptibility or disease) not disclosed during evaluation, possibly unknown even to the patient (allergic reaction for which history data was inconclusive; severe root resorption and demineralisations present in association with a metabolic disease unidentified at the initial assessment);

- conditions arising as a result of a passive operator intervention, associated with a lack of proper monitoring (lack of monitoring and proper prevention methods in cases with severe root resorption or decalcifications);

- medical errors by wrongful medical objectives and deficient treatment conduct (enamel damage due to improper debonding technique; tooth movement into an area with alveolar bone defect causing severe loss of attachment).

\section{Presentation of the main complications linked to orthodontic intervention}

Like any other medical intervention, the orthodontic treatment may have, besides the positive effects, also unwanted secondary consequences. In the scientific literature there are numerous conditions to which orthodontic treatment may be associated (Table 2) (Ellis \& Benson, 2002; Graber et al., 2004; Lau \& Wong, 2006). For most of them a direct cause-efect relation hasn't been proven, but for no reason these aspect should be neglected.

\subsection{Dental complications}

Linked to orthodontic intervention, there are described numerous side effects present on tooth level. Among the first etiological hypothesis was the one saying that fixed orthodontic technique may induce enamel changes, both quantitatively (enamel loss during bonding and debonding procedures) and qualitatively (discolorations). On root level the most unwanted side effect taken into consideration in the medical literature is severe root resorption, process associated with root shortening that may lead to an insufficient tooth ability to endure the forces present during oral function performance and in extreme cases early tooth loss. Regarding the pulpal reactions, during action of orthodontic forces may appear a decreased oxygenation of pulpal tissue, varying in the same direction with force magnitude and period of action. Usually the inflammatory reactions that appear are transitory, reversible, but severe modifications, like necrosis, sometimes appear. Greater risk of pulpal reactions is present in teeth with a history of severe periodontal injury during certain orthodontic procedures, e.g., during intrusion and extrusion (Bauss et al., 2008; Bauss et al., 2010).

\subsubsection{Enamel damage during bonding and debonding of the orthodontic devices}

Enamel damage that appears as a side effect of the orthodontic therapy is relatively largely related to the bonding and debonding technique. One of the main preoccupations within the 
current orthodontics is identifying the ways to obtain, at the end of the treatment, a sound, unmodified enamel surface.

SIDE EFFECTS AND COMPLICATIONS

HYPOTHETICALLY LINKED TO ORTHODONTICS

LOCAL EFFECTS

Dental

- crown: decalcifications, decays, tooth wear, enamel cracks and fractures; discolorations, deterioration of prosthetic crown (as fracturing a ceramic one during debonding);

- root: root resorption, early closure of root apex, ankylosis;

- pulp: ischemia, pulpitis, necrosis;

\section{Periodontal}

- gingivitis, periodontitis, gingival recession or hypertrophy, alveolar bone loss, dehiscences, fenestrations, interdental fold, dark triangles;

Temporomandibular joint

- condylar resorption, temporomandibular dysfunction;

Soft tissues of the oral and maxillofacial region

- trauma (e.g., long archwires, headgear related), mucosal ulcerations or hyperplasia, chemical burns (e.g., etching related), thermal injuries (e.g., overheated burs), stomatitis, clumsy handling of dental instruments;

\section{Unsatisfactory treatment outcome}

- inadequate morpho-functional, aesthetic or functional final result, relapse, failure to complete treatment due to treatment dropout.

SYSTEMIC EFFECTS

\section{Psychological}

- $\quad$ teasing, behavioral changes of patients and parents; discomfort associated with pain presence and aesthetic look discontents during orthodontic appliance usage;

\section{Gastro-intestinal}

- accidental swallowing of small parts of the orthodontic device (tubes, brackets);

Allergies to nickel or latex;

Cardiac

- infective endocarditis;

\section{Chronic fatigue syndrome;}

Cross infections

- $\quad$ from doctor to patient, patient to doctor, patient to patient.

Table 2. Main risks and complications associated with the orthodontic treatment.

Before applying brackets, tubes and bands, it is recommended to prepare the surface by pumice prophylaxis in order to increase the bond strength, procedure with great importance especially when self-etched adhesives are used as bonding material (Lill et al., 2008). Cleaning and pumicing procedures are accompanied by enamel loss and fissures on its surface, but these alteration present very low severities, neglectable compared to the ones present after debonding (Øgaard \& Fjeld, 2010; Hosein et al., 2004). 
By current knowledge, bonding of orthodontic appliances may induce irreversible changes of tooth surface. The most severe modifications appear when resins (especially the conventional ones, with a separate etching phase) are used as bonding materials. The bond strength of these materials is directly related to the resin tags formed, that cannot be removed at orthodontic treatment end. The extent of etching depth depends on numerous factors, among those being the acid type and concentration, time of application, enamel surface characteristics (e.g., in the mandibular molars and premolars usually is present aprismatic enamel that is more resistant to etching, aspect that could contribute to the observed higher debonding failure rate of bracket and tubes). Sometimes, after bracket bonding, demineralised enamel remains uncovered by resin, but usually remineralisation occurs, this not being a risk factor for decay appearance. A more recent bonding technique is the one with self-etched adhesive resin, which produces less enamel damage but has the disadvantages of lower bond strength. Resin-modified glass ionomer cement are preferred as bonding materials due to the reduced enamel involvement, fluor releasing properties and bond strength similar to resins. Fjeld, analyzing enamel alteration after 3 variants of bonding materials (conventional resin with $35 \%$ phosphoric etching gel and bonding/resin Transbond XT, 3M Unitek; self-etching adhesives - Transbond Plus, 3M Unitek; resinmodified glass ionomer cement - Fuji ORTHO LC, GC Corporation used after surface conditioning with $10 \%$ polyacrylic acid) observes that the most important changes were associated to the first material usage (thick and relative deep - 10-20 $\mu \mathrm{m}$ - resign tags accompanied by an increased surface rugosity). Less severe modifications were observed for the second material (smaller, fewer and less profound - 5-10 $\mu \mathrm{m}-$ resin tags). When Fuji ORTHO LC was used no resign tags were observed. Authors conclude that by using the last two variants of bonding material advantages in term of fewer irreversible changes of the enamel surface are present (Fjeld \& Øgaard, 2006).

During debonding and removal of the residual material there is a risk of tooth damage (enamel loss, cracks), irreversible complication being seen as hard to avoid. Frequency and gravity of enamel loss is usually smaller when metallic braces and bonding materials based on glass ionomer cements are used. More severe modifications were seen when ceramic brackets and adhesive resins were used as bonding materials. The orthodontist has a big role in preventing this irreversible enamel damage by using an appropriate debonding technique. A safe debonding technique aims to break the link between bracket and adhesive, this being preferred especially when adjacent to the bracket base there is softened, demineralised enamel. The residual bonding material is better to be removed with tungsten carbide burs at low speed, followed by surface polishing with pumice or a paste, in order to decrease rugosity and prevent plaque accumulation (Graber et al., 2004). Horizontal enamel cracks present after debonding are associated directly with the orthodontic technique, the vertical ones being present with a high frequency also in the population without previous orthodontic treatment (Øgaard \& Fjeld, 2010).

In order to study enamel changes associated with orthodontic treatment we analyzed 2 pairs of upper premolars with a history of orthodontic treatment (treatment duration of 12 and 23 moths), extracted for orthodontic purposes after treatment plan was reassessed. By microscopic analysis, using magnifications till 5X, on the buccal surface there were identified changes in terms of color and roughness, with clear identification of the area where the bracket was applied. The enamel area corresponding to the bracket's base 
presented a uniform, white aspect. The enamel area corresponding to the margins of the bracket was assessed as having an irregular aspect, with more severe alteration in the gingival region compared to the occlusal one. The enamel lingual area (considered as control) presented an aspect considered as being uniform (Fig. 1). An increased surface roughness was observed at the area correspondent to the bracket's base, this being probably associated with the resin adhesive material used for bracket bonding (Preoteasa et al., 2011a). Using magnifications of 20X, on the buccal tooth surface were observed multiples unordered fissures, caused probably by the bracket debonding and residual material removal technique. The lingual surface presented also cracks, but fewer, this being probable associated to the occlusal contacts. By analyzing the buccal surface of two newly erupted premolars, without history of orthodontic treatment, a uniform aspect, crack and fissure free surface was observed (Fig. 2).

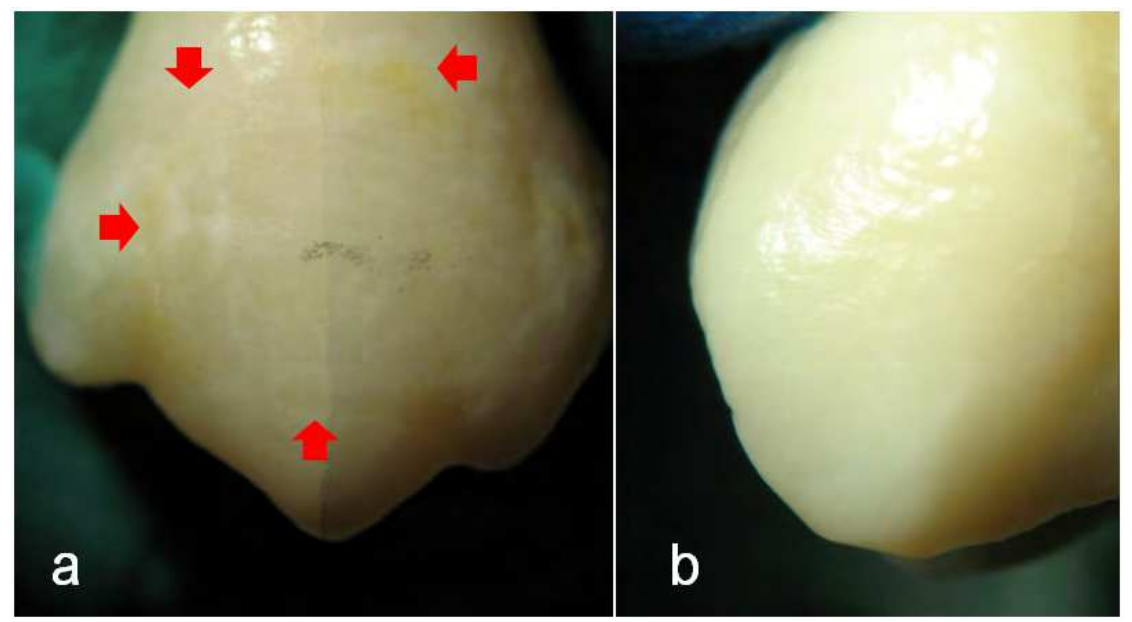

Fig. 1. Microscopic aspect of the enamel surface of a maxillary first premolar with a history of orthodontic treatment - buccal enamel surface (a); lingual enamel surface (b) magnification 5X.
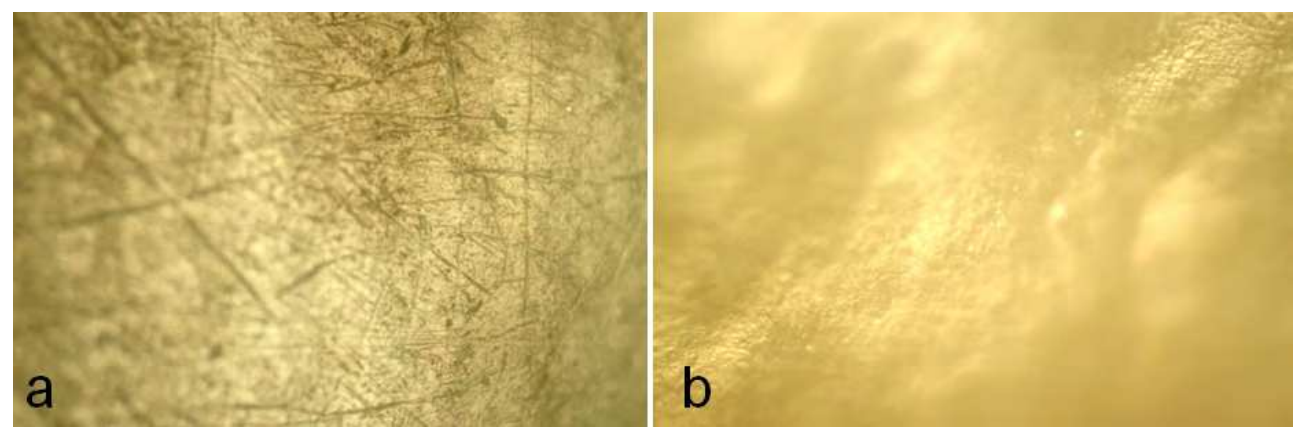

Fig. 2. Microscopic evaluation of buccal enamel surface for two upper first premolars, one with a history of orthodontic treatment (a); one without previous orthodontic treatment (b) magnification 20X. 


\subsubsection{Carious complications associated with the orthodontic intervention}

As the orthodontic technique developed, concerns regarding tooth damage by carious lesions during treatment increased, this being seen today as one of the most frequent unwanted side effect associated with this particular medical intervention. Decay damage associated with orthodontic technique presents some specific particularities. They appear with increased frequency on the tooth's surface where the bracket is bonded, adjacent to its base, they usually have low severity (most of the times are encountered as white spot lesions, more frequently gingival and distal to the bracket's base than mesial or occlusal) (Fig. 3). Evidence shows that the prevalence of this unwanted side effect is nearby $70 \%$ for white spot lesions and less than 5\% for cavities (Al Maaitah et al., 2011). According to Chapman's study more than $30 \%$ of the maxillary incisors, teeth with the greatest esthetic values, present decalcifications after orthodontic intervention (Chapman et al., 2010).

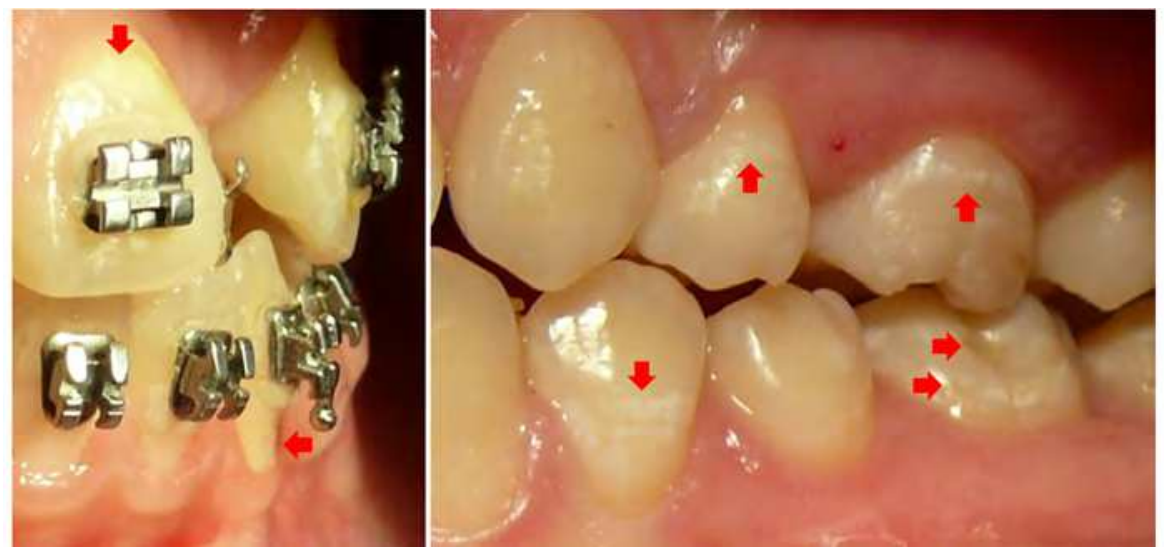

Fig. 3. White spot lesions and cavities related to the presence of orthodontic appliance.

Demineralisations around brackets occur mainly due to improper oral hygiene maintenance. But, in the presence of orthodontic appliance, an increased number of plaque retention areas appear, accompanied by a decrease of the self cleaning. In orthodontic patients plaque coverage is 2 to 3 times higher than the levels present in high plaque forming adults without this type of treatment (Klukowska et al., 2011). It is also observed a decrease of salivary pH and increased level of Streptococcus Mutans and Lactobacillus, elements favoring carioactivity (Vizitiu \& Ionescu, 2010). Thus, maintaining a good oral hygiene is mandatory. Also, learning new skills on how to perform oral hygiene and using additional instruments may be needed, e.g., like interdental brush. Consequently, there are higher costs implied, not only financial (the tooth brush wears faster, investments in auxiliary devices like interdental brush or oral shower), but also time-related (more time spent for ensuring a good oral hygiene).

In decay prevention, even if the patient has the main role by maintaining a good oral hygiene, the orthodontist's role isn't neglectable. Before starting the orthodontic therapy it is recommended to evaluate carioactivity and oral hygiene habits, these being sometimes reasons to postpone orthodontic treatment with fixed appliance. Primary prevention methods may be used (e.g., recommendation of how to maintain a good oral hygiene and 
regarding diet; usage of fluoride releasing materials for bracket bonding and bands cementation). When necessary, secondary prevention methods must be promptly applied (e.g., increasing patient's compliance through operator's active intervention when white spot lesions are observed). One method for decreasing carioactivity, frequently used by orthodontists and dental practitioners, is fluorisation. A systematic review made in 2004 concludes that there is some evidence that supports the hypothesis that daily fluoride mouthrinse or fluoride-containing cement reduces tooth decay during treatment with fixed braces (Benson et al., 2004). A split-mouth study on this theme is the one made by Shungin reported in 2010, with a 12 years follow-up after active treatment ended. Results show that at the end of the treatment a significant increase of white spot lesion frequency was present, this being followed by a significant progressive decreasing. Also, modifications were significantly less severe in all moments when glass ionomer cement was used as bonding material, compared to the acrylic one (Shungin et al., 2010). Different treatment alternatives may be used when white spot lesions are present at treatment end, among these being: waiting for spontaneous remineralisation, usage of fluor or casein phosphopeptide based products, recommendation to chew sugar-free gums. In frontal teeth, when aesthetic complaints are present, microabrasion may be used.

For a better knowledge of orthodontic biomaterials, needed in order to adequate select them, we made an experiment to comparatively evaluate the surface wettability of some orthodontic bonding materials. 4 commercial products were chosen, different 2 by 2 as type of material and as curing method. Surface wettability was assessed by contact angle measurements using KSV Instruments's CAM 101 device (KSV Instruments, 2008). Results showed that for both glass ionomer cements and composite resins curing mechanism influenced wetting properties, the light curing ones presenting lower contact angle values than the self-curing ones. Also, analyzing the materials with the same curing characteristics, acrylic resins presented higher contact angles than the glass ionomer cements (Table 3). Surface wettability is linked to hidrophylicity and microbial adherence. When choosing between materials with the same clinical use, namely bonding of orthodontic brackets, in order to prevent caries apparition, in high risk patients the practitioner may prefer the chemically-cured composite resin, which is more hydrophobic and theoretically predispose less to plaque accumulation. Regarding glass ionomer cements, that are frequently used for band cementation, in time, due to their hydrophilic character and due to the fact that solubilization can take place, it may appear a space which represents a retention zone for the dental plaque, becoming an etiologic agent for decay and periodontitis. Of course, other properties must be analyzed in order to choose the best suited material for each case, but knowing surface properties may help in this direction and also explain some noticed clinical aspects (Preoteasa et al., 2011b).

\begin{tabular}{|c|c|c|c|c|c|}
\hline \multirow{2}{*}{$\begin{array}{c}\text { Commercial } \\
\text { product }\end{array}$} & \multirow{2}{*}{ Producer } & \multirow{2}{*}{$\begin{array}{c}\text { Type of } \\
\text { material }\end{array}$} & \multirow{2}{*}{ Curing method } & \multicolumn{2}{|c|}{ Contact angle } \\
\hline & & & & mean & SD \\
\hline Resilience & \multirow{2}{*}{$\begin{array}{c}\text { Ortho } \\
\text { Technology }\end{array}$} & \multirow{2}{*}{$\begin{array}{l}\text { composite- } \\
\text { based resin }\end{array}$} & light-cured & $48.45^{\circ}$ & 3.68 \\
\hline Resilience & & & chemically cured & $64.91^{\circ}$ & 3.40 \\
\hline Fuji Ortho LC & \multirow{2}{*}{ GC Europe } & \multirow{2}{*}{$\begin{array}{c}\text { glass ionomer } \\
\text { cement }\end{array}$} & light cured & $35.04^{\circ}$ & 0.81 \\
\hline Fuji PLUS & & & self cured & $56.59^{\circ}$ & 3.52 \\
\hline
\end{tabular}

Table 3. Contact angle values for some orthodontic materials, with details regarding their characteristics. 


\subsubsection{Color alterations linked to the orthodontic treatment}

Discoloration present after braces removal may have a negative impact on the aesthetics and patient's satisfaction. Karamouzos et al. in a split-mouth study on 26 orthodontic patients reported that teeth's color parameters changed after orthodontic treatment, $80 \%$ of the patients presenting at least one tooth with discolorations appreciated by authors as being unacceptable. Time had an aggravating effect on all color parameters evaluated according to the Commission Internationale de l'Eclairage system ( $\mathrm{L}^{*}$-lightness; $\mathrm{a}^{*}$-red/green; $\mathrm{b}^{*}$ blue/yellow). There were observed more severe alteration when chemically cured resins were used as bonding material compared to light cured composites (Karamouzos et al., 2010).

Color alterations after orthodontic treatment present a multifactorial etiology, some variables being directly linked to the technique itself. Frequency of these alterations is considerably higher, with increased severity, when fixed appliances are used in comparison with the removable ones. When resins are used for bracket bonding enamel changes are unavoidable (Fig. 4). The resin tags cannot be removed by cleaning procedures without altering considerably the enamel surface. Irreversible changes regarding enamel surface morphology, its rugosity and texture are present, with negative influences on reflection properties, luminosity and optical perception. Evidence shows that adhesives resins used for bracket bonding don't present good color stability in time. Food dyes, ultraviolet light and corrosion products from the orthodontic appliance induce color alterations, with a tendency to modify toward the yellow tones (Faltermeier et al., 2008). In the presence of orthodontic forces that induce variation in pulp vascularization, it is also possible that endogenous discoloration appear, with a premature aging of tooth. Also, if white spots lesions are present, even if remineralisation occurs, most probable the final outcome will be somehow different from the initial enamel structure, the mineral not being identical disposed as in the unaffected enamel, with possible influences on color properties.
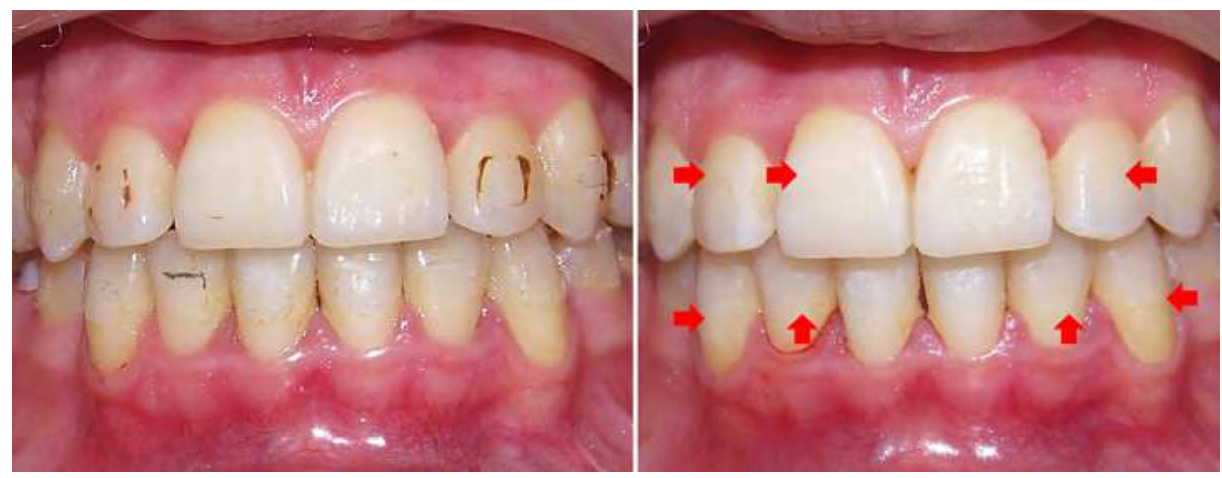

Fig. 4. Color changes integrated to usage of composite resins for bracket bonding.

After bracket removal patients frequently wish to increase their appearance by teeth whitening. This procedure presents particularities especially when resins were used as bonding material, due to the remained resins tags. The residual adhesive behaves different compared to adjacent enamel during whitening, being important to accurately evaluate the situation in order to avoid producing a more unpleasant outcome. 


\subsubsection{Dental wear associated to the use of orthodontic appliances}

Another dental alteration present in the orthodontic patient is tooth wear secondary to the contact between teeth and brackets or tubes. A higher gravity of this process was noticed when ceramic brackets are used, Viazis reporting a severity from 9 to 38 times higher compared to the metallic ones (Lau et al., 2006; Viazis et al., 1990).

It is recommended, especially during certain phases of orthodontic treatment, to avoid usage of ceramic brackets in order to minimize the dental wear, as an irreversible treatment complication. For example, when deep bite is present, ceramic brackets on the lower anterior teeth shouldn't be used until sufficient overjet is created in order not to favor wear of the maxillary incisors, side effect with an increase negative impact on the esthetic dimension of the final result. Precautions must be taken when using the ceramic attachment on canine that are in a class II relationship and also during maxillary incisors retraction (Graber et al., 2004).

\subsubsection{External apical root resorption in orthodontic therapy}

Apical root resorption is, according to the present knowledge, an unavoidable complication of the orthodontic treatment, microscopic studies showing a prevalence of $100 \%$ after the treatment end (Fig. 5 \& 6). Segal et al., in a systematic review reported in 2004, using metaanalysis, found a mean value of the root shortening after orthodontic treatment of $1.421+/$ $0.448 \mathrm{~mm}$ (Segal et al., 2004). Usually, the process severity is low, root shortening beyond $2 \mathrm{~mm}$ being present in $5-18 \%$ of cases, and beyond $4 \mathrm{~mm}$ or $1 / 3$ of tooth length in $1-5 \%$ of the cases (Lopatiene \& Dumbravaite, 2008).
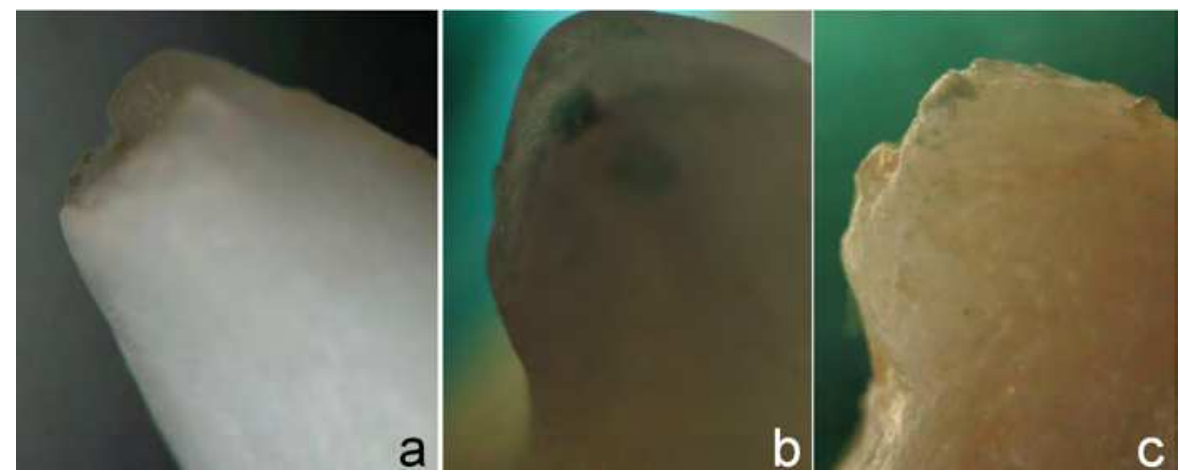

Fig. 5. Aspect of apical third of root of a newly erupted premolar (a), an included molar (b) and a premolar extracted for orthodontic purposes (c) - magnification $4 \mathrm{X}$.

Root resorption's signs and symptoms are usually absent, even mobility been rarely higher than $1^{\text {st }}$ degree on the Miller scale. If in the end of the treatment the root resorption's severity is mild or moderate the tooth prognosis doesn't greatly decrease. Kalkwarf demonstrated that $4 \mathrm{~mm}$ root shortening due to this pathological aspect is equivalent to $20 \%$ loss of the periodontal attachment, and $3 \mathrm{~mm}$ loss equivalent to $1 \mathrm{~mm}$ loss of the periodontal attachment (Kalkwarf et al, 1986). The high severity forms of root resorption, corresponding to considerable root shortening with influence on tooth prognosis, are one of the most 
discussed complications in association with the orthodontic therapy, being perceived as an unpredictable consequence with insufficient knowledge about its treatment alternatives and evolution.

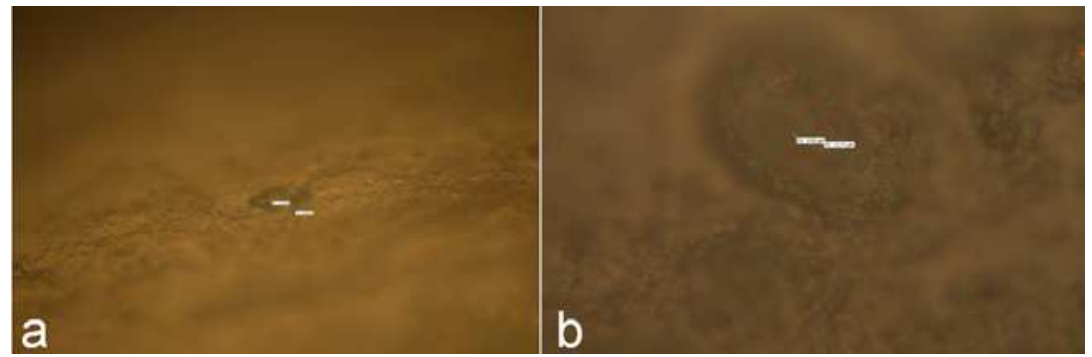

Fig. 6. Resorption lacunae in teeth without (a) and with (b) a history of orthodontic treatment - diameter: (a) $0.72 \mu \mathrm{m}$; (b) $12.11 \mu \mathrm{m}$ - magnification $20 \mathrm{X}$.

In order to minimize the severity of root resorption a good knowledge of etiopathogenic mechanism is mandatory. Although this aspect presents a series of ambiguities, mainly two categories of factors are incriminated for root resorption appearance, namely related to patient characteristics and to orthodontic technique. Both issues are important to be assessed, the first ones in order to identify high risk patients, and the last ones in order to ensure an orthodontic intervention predisposing at minimum to this unwanted side effect.
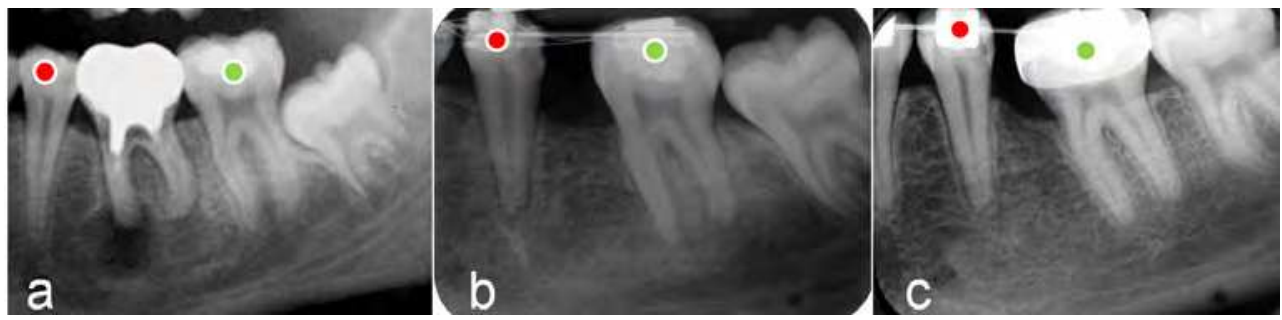

Fig. 7. Patient with identified susceptibility toward root resorption; mandibular first molar with root resorption signs, having as presumed cause incorrect endodontic treatment (a); progressive resorption at the mandibular second molar and premolar after orthodontic intervention was applied $(b, c)$.

By current scientific knowledge, individual susceptibility has the main role in root resorption appearance, aspect difficult to correctly estimate. Indicators of high risk patients may be the signs of root resorption prior to orthodontic therapy, regardless of the presumed cause, and the presence of root resorption in the first degree relatives (Fig. 7). Genetic factors play an important part in root resorption presence, some associations, like the one with the polymorphism of the IL-1beta gene being demonstrated (Bastos Lages et al., 2009). Some study results suggest that this unwanted side effect is different between ethnic groups. Among Asians there is a decreased frequency of root resorption compared to Caucasians or Hispanics (Lopatiene \& Dumbravaite, 2008). Modified general health status has been linked to a more severe root resorption process, among the diseases more frequently associated being allergies, asthma, diabetes, arthritis and endocrine disorders (Graber et al., 2004). An 
increased frequency of root resorption was associated to abnormal eruption path, the mechanism considering the pressure of the included tooth on the adjacent tooth roots. It has been mainly observed as being present in the second molars (produced by pressure of the wisdom teeth) and in the lateral incisor or first premolar (pressure exerted by the canine). Open bite is currently seen as a risk factor for root resorption, arguments being linked to the insufficient development of the periodontal tissue of the interested teeth, being incapable to bear orthodontic and occlusal forces, present during oral functions. Other dental anomalies associated with this particular complication are: hypodontia, class II and III Angle, deep bite and increased overjet (Lopatiene \& Dumbravaite, 2008; Preoteasa et al, 2009). One aspect confirmed by many study results is that there is a direct relation between root morphology and root resorption process. A greater risk of root resorption present teeth with long and narrow roots, with abnormal root shape in the apical part of the root, especially eroded, pointed, deviated or bottle shape (Artun et al., 2009; Smale et al., 2005). Depending on the tooth's topography root resorption process presents some variability. Maxillary teeth are more prone to develop root resorption compared to the mandibular ones, and frontal teeth more prone than lateral ones (Brezniak \& Wasserstein, 2002). Generally it is said that the more resorbed teeth, in a decreasing sequence, are the following: maxillary lateral incisors, maxillary central incisors, lower incisors, maxillary canines, first molars, lower second premolars and maxillary second premolars (Lopatiene \& Dumbravaite, 2008). Also teeth with trauma history present a higher risk of root resorption (Artun et al., 2009).

Among risk factors of root resorption related directly to orthodontic technique the most important seem to be: treatment time, the amount of root apex displacement, the type and amount of orthodontic force, and also the type of orthodontic appliance used (Fox, 2005; Segal et al., 2004). Most study results indicate that one of the most important factor in root resorption appearance is treatment duration, an optimal period in order to prevent severe root resorption being less than 1/1/2 years (Apajalahti \& Peltola, 2007). A higher frequency of root resorption was linked to intrusion, expecialy when vestibular coronal torque was associated. Heavy and continuous forces are correlated with significantly more root resorption. Type of used orthodontic appliance influences root resorption process, being less severe in treatment delivered by removable orthodontic devices and higher when disjunction and extraoral appliances are used. Current knowledge indicates that bracket prescription and type (e.g., standard edgewise or straight wire technique, conventional or self-ligating) doesn't influence root resorption severity (Weltman et al., 2010.).

Considering the negative impact of severe root resorption it is recommended that the orthodontist take the necessary measures in order to prevent it from happening. During the initial evaluation, the patients with a high risk to develop root resorption should be identified, by considering previous signs of root resorption and local and systemic risk factors. If a patient with a high risk of root resorption is identified, reassessing the treatment objectives is recommended (whenever possible is best to avoid teeth extractions, heavy and continuous forces, disjunction, long treatment duration). In all cases it is recommended, at approximately 6 month after placement of orthodontic appliance, to acknowledge if root resorption signs appeared by analyzing periapical radiographs, at least for the frontal teeth. If, by that moment, there aren't signs of root resorption, the risk of presenting severe risk resorption at the end of the treatment is usually minimal. If, at that moment, sign of root resorption are present most likely during treatment some progressive modification will appear. Evidence shows that 2-3 months pause in orthodontic treatment, with passive wires, 
decreases the total amount of root resorption (Weltman et al., 2010). If severe signs of root resorption are present the treatment plan must be reassessed. Treatment alternatives may include prosthodontic solution for space closing, striping instead of extractions, sometimes even discontinuing orthodontic therapy. If severe root resorption is present after the active phase ended it is recommended radiological monitoring till process stabilizes. If a progressive evolution is noticed, frequently factors like occlusal trauma or retention devices that continue to develop orthodontic forces are associated, being necessary to address these items.

In order to study some aspects related to the etiology of root resorption, the authors designed and implemented a cross-sectional study who aimed to see if there is a correlation between root resorption's severity and some of the individual particularities that can be assessed before treatment start. A convenience sample of 55 orthodontic patients $(74.5 \%$ $\mathrm{n}=41$ females and $25.5 \%-\mathrm{n}=14$ males) treated in the Department of Orthodontics and dentofacial orthopedics from the Faculty of Dental Medicine, Bucharest, from October 2005October 2009, was used. Inclusion criteria were: orthodontic patients with fixed metallic appliance, standard edgewise or straight-wire technique, applied bimaxillary for at least 6 months. Patients with previous orthognathic interventions, disjunction, radiological signs of root resorption before treatment start, missing or endodontically treated incisors were excluded. Root resorption was assessed by measurements on panoramic radiographs using the Linge and Linge formula and Adobe Photoshop software, version 6.0 (Linge \& Linge, 1991). In order to quantify the extent of root resorption for each patient included in the sample, two indices were used: average root resorption (mean value of root resorption registered for the 8 measured incisors in each patient, registered in $\mathrm{mm}$ ) and the maximum root resorption (maximum value of root resorption from the 8 measured incisors in each patient, registered in $\mathrm{mm}$ ). Data collection for the study variables was made using patient's file, photographs, study casts and cephalometric evaluation on teleradiographs. For data analysis STATA statistical software, version 11, was used. The sample presented mostly mild or moderate apical root resorption, with an average value of $1.31 \mathrm{~mm}$ (standard deviation 0.60 ). The study evidenced a moderately positive statistically-significant correlation between average root resorption and the value of FMA angle, suggesting that patients with hyperdivergent facial pattern have a more pronounce tendency to develop root resorption after the orthodontic intervention, compared to the hypodivergent ones. Also our results suggest that patients with skeletal open bite tend to be more severely affected by external root resorption (Table 4). By comparing data regarding the root resorption among subgroups (made according to the normal and, respectively abnormal values of the parameters registered from their cephalometric assessment and dental evaluation) some additional information were obtained. Within the subgroups made according to the values of the parameters that evaluate the sagittal skeletal relations, the mean values of root resorption indices evidenced a more severe process in patients with values different from the average. The difference between groups was not statistically significant. Analysis of the subgroups constituted according to the value of the parameters selected for vertical skeletal relations evidenced the tendency of a more severe modification in the cases with higher values than the average (Preoteasa \& Ionescu, 2011). Patients with Angle class II or III malocclusion presented more severe modifications than those belonging to class I (Table 5). In conclusion we can say that the pathological process of external root resorption is a reality accompanying frequently the orthodontic intervention, its severity 


\begin{tabular}{|c|c|c|c|c|}
\hline \multirow{2}{*}{$\begin{array}{c}\text { Cephalometric } \\
\text { parameter }\end{array}$} & \multicolumn{2}{|c|}{ Mean root resorption } & \multicolumn{2}{|c|}{$\begin{array}{c}\text { Root resorption with } \\
\text { maximum severity }\end{array}$} \\
\hline & $\begin{array}{l}\text { Correlation } \\
\text { coefficient }\end{array}$ & p-value & $\begin{array}{c}\text { Correlation } \\
\text { coefficient }\end{array}$ & $\mathrm{p}$-value \\
\hline SNA1 $^{1}$ & -0.082 & NS & -0.128 & NS \\
\hline $\mathrm{SNB}^{1}$ & -0.058 & NS & -0.127 & NS \\
\hline $\mathrm{ANB}^{2}$ & -0.008 & NS & 0.040 & NS \\
\hline FMA $^{1}$ & 0.303 & $0.024^{*}$ & 0.316 & $0.019^{*}$ \\
\hline SNA-SNP/Go-Gn² & 0.228 & NS & 0.275 & $0.042^{*}$ \\
\hline Z-angle $^{1}$ & -0.180 & NS & -0.219 & NS \\
\hline Total chin ${ }^{2}$ & 0.282 & $0.037^{*}$ & 0.276 & $0.041^{*}$ \\
\hline 1 Pearson & \multicolumn{4}{|l|}{${ }^{*}-\mathrm{p}<0.05$} \\
\hline 2 Spearman & \multicolumn{4}{|c|}{ NS - not significant } \\
\hline
\end{tabular}

Table 4. Correlations between root resorption and craniofacial particularities.

\begin{tabular}{|c|c|c|c|c|c|c|c|}
\hline \multirow{2}{*}{ Parameter } & \multirow{2}{*}{ Group } & \multicolumn{3}{|c|}{ Mean root resorption } & \multicolumn{3}{|c|}{$\begin{array}{c}\text { Root resorption with } \\
\text { maximum severity }\end{array}$} \\
\hline & & Mean(SD) & Test & p-value & Mean(SD) & Test & p-value \\
\hline \multirow{3}{*}{ SNA } & $<80$ & $1.44(0.66)$ & \multirow{3}{*}{1} & \multirow{3}{*}{ NS } & $3.11(1.32)$ & \multirow{3}{*}{1} & \multirow{3}{*}{ NS } \\
\hline & $80-84$ & $1.18(0.48)$ & & & $2.40(0.88)$ & & \\
\hline & $>84$ & $1.38(1.00)$ & & & $2.63(1.68)$ & & \\
\hline \multirow{3}{*}{ SNB } & $<78$ & $1.37(0.65)$ & \multirow{3}{*}{1} & \multirow{3}{*}{ NS } & $2.89(1.26)$ & \multirow{3}{*}{1} & \multirow{3}{*}{ NS } \\
\hline & $78-82$ & $1.15(0.53)$ & & & $2.43(1.04)$ & & \\
\hline & $>82$ & $1.64(0.55)$ & & & $2.85(1.11)$ & & \\
\hline \multirow{3}{*}{ ANB } & $<0$ & $1.31(0.47)$ & \multirow{3}{*}{1} & \multirow{3}{*}{ NS } & $2.64(1.08)$ & \multirow{3}{*}{2} & \multirow{3}{*}{ NS } \\
\hline & $0-4$ & $1.23(0.57)$ & & & $2.54(1.05)$ & & \\
\hline & $>0$ & $1.51(0.74)$ & & & $3.11(1.42)$ & & \\
\hline \multirow{3}{*}{ FMA } & $<22$ & $1.05(0.56)$ & \multirow{3}{*}{1} & \multirow{3}{*}{ NS } & $2.29(0.91)$ & \multirow{3}{*}{2} & \multirow{3}{*}{$0.040^{*}$} \\
\hline & $22-28$ & $1.34(0.58)$ & & & $2.57(1.02)$ & & \\
\hline & $>28$ & $1.52(0.62)$ & & & $3.26(1.37)$ & & \\
\hline \multirow{3}{*}{$\begin{array}{c}\text { SNA-SNP/ } \\
\text { Go-Gn }\end{array}$} & $<<19$ & $1.04(0.55)$ & \multirow{3}{*}{1} & \multirow{3}{*}{ NS } & $2.32(0.95)$ & \multirow{3}{*}{2} & \multirow{3}{*}{$0.004^{*}$} \\
\hline & 19-31 & $1.30(0.50)$ & & & $2.49(0.90)$ & & \\
\hline & $>31$ & $1.62(0.78)$ & & & $3.64(1.51)$ & & \\
\hline \multirow{3}{*}{ Z-angle } & $<<70$ & $1.39(0.67)$ & \multirow{3}{*}{1} & \multirow{3}{*}{ NS } & $2.87(1.33)$ & \multirow{3}{*}{1} & \\
\hline & $70-80$ & $1.29(0.55)$ & & & $2.63(1.11)$ & & NS \\
\hline & $>80$ & $1.16(0.58)$ & & & $2.50(0.85)$ & & \\
\hline & $\overline{\mathrm{I}}$ & $1.14(0.69)$ & & & $2.34(1.96)$ & & \\
\hline Angle class & II & $1.30(0.49)$ & 1 & NS & $2.73(1.05)$ & 1 & NS \\
\hline & III & $1.57(0.62)$ & & & $3.15(1.25)$ & & \\
\hline $\begin{array}{l}{ }^{1} \text { Kruskal Wa } \\
{ }^{2} \text { Anova }\end{array}$ & & & & $\begin{array}{l}*-\mathrm{p}<0 . \\
\mathrm{NS}-\mathrm{no}\end{array}$ & nificant & & \\
\hline
\end{tabular}

Table 5. Root resorption among groups of patients structured according to the normality of investigated parameters. 
being associated at some extent with the individual morphological characteristics. A good knowledge on the variables associated to severe root resorption is essential for the identification of the high risk patients, as well as for the selection of the best suited treatment alternative in terms of low probability of root resorption occurrence.

\subsection{Periodontal complications}

Periodontal complications are one of the most actual side effects linked to the orthodontics, not rarely being the reason for malpractice complaints. It can be found in various forms, from gingivitis to periodontitis, dehiscence, fenestrations, interdental fold, gingival recession or overgrowth, black triangles (Fig. 8). Severe damage can considerably interfere with the teeth prognosis. Etiopathogeny is complex, involving factors related to the patient (e.g., previous condition present, increased susceptibility, poor oral hygiene) and to orthodontic technique.

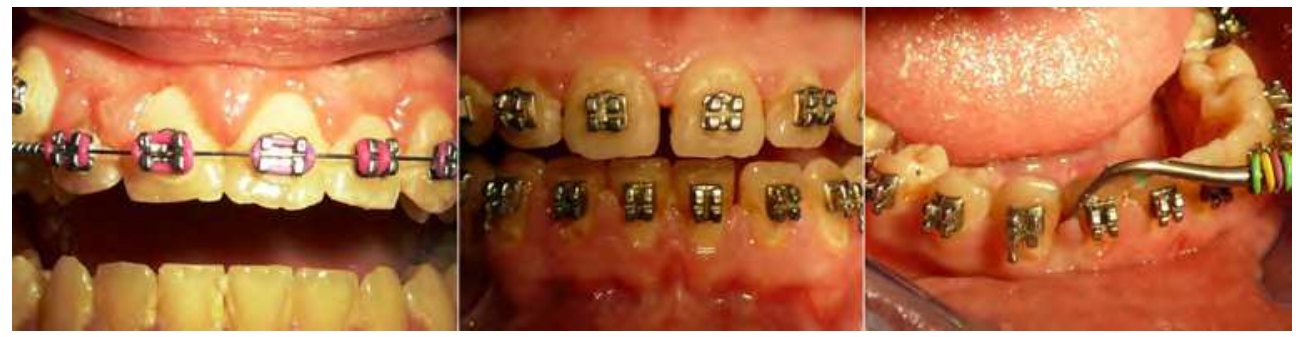

Fig. 8. Periodontal alteration present during orthodontic treatment.

Gingivitis usually occurs due to the incorrect maintenance of the oral hygiene, in the presence of the orthodontic appliance, that seems to favor plaque accumulation. Their frequency is increased in some particular situations, like in the presence of orthodontic bands that usually are placed subgingival, accompanied sometime by the solubilisation of luting agent, favoring the gingival overgrowth by mechanical trauma and existence of retention space for plaque accumulation. This is why, in order to ensure a safer medical care, bondable tubes are more indicated than bands. Even so, research has shown that during orthodontic therapy gingival enlargement occurs, but approximately 3 month after the removal of the appliance, in most cases, the gingiva presents a similar aspect as before treatment (Kouraki et al., 2005).

Careful management of orthodontic treatment is recommended when previous periodontal alterations are identified. Orthodontic intervention may aggravate a previous condition, which may lead to severe disease form, sometimes difficult to control. In these cases is best to postpone the treatment till a very good oral hygiene is present and the periodontal disease is stable. During the initial assessment, patients with factors that predispose to worsening the periodontal condition (e.g., presence of diabetes or epilepsy treated with drugs that induce gingival enlargement) need to be identified. During orthodontic therapy it is recommended to insist on the importance of maintaining a good oral hygiene, to monitories the periodontal status (at least every three month to do an examination and dental cleaning) and to take the necessary measures in order to control the risk factors. Also orthodontic therapy should be particularized, e.g., by choosing the treatment alternative 
who favors less accumulation of plaque, devices as simpler as possible and developing small orthodontic forces. In this regard it is recommended to avoid as much as possible hooks, elastic ligatures and chains, bands being preferable to tubes, and metallic ligatures to elastomeric ones.

During some particular orthodontic interventions an increased frequency of periodontal complications was noticed. For example, within extraction treatment after space closure, a higher frequency of periodontal interdental folds, associated sometimes with gingival enlargement, were observed (Fig. 9). Also after moving teeth in the buccal-lingual direction, as in the expansion or intermaxillary disjunction, the risk of fenestrations and dehiscences is higher. In this context it is recommended to choose the treatment alternative that predisposes as little as possible to these impairments.

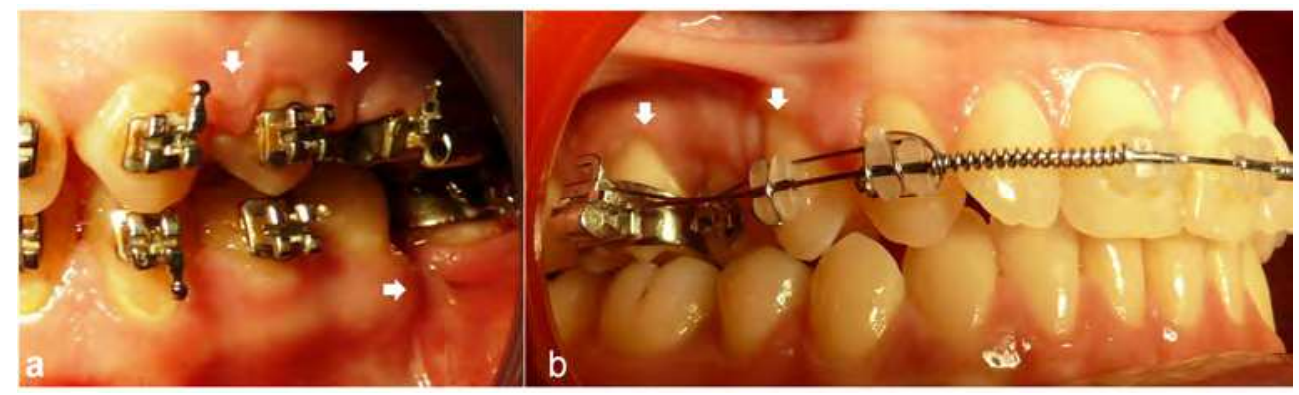

Fig. 9. Periodontal complications - gingival enlargement, interdental fold - present during orthodontic therapy (a); Gingival recessions associated with crossbite malocclusion, not linked to the orthodontic appliance's presence (b).

\subsection{Soft tissue alterations}

During orthodontic treatment intra- and extraoral (face and neck) soft tissue alterations may appear. For the oral lesions, the etiological mechanism involves the direct contact of gingiva and mucosa with brackets, bands, tubes and arches, and it is also related to the incorrect handling of the orthodontic instruments. The outcome usually consists in erosions and ulcerations on the buccal, labial, lingual or gingival mucosa. Pain and discomfort are associated, but by using orthodontic wax it may be possible to ameliorate to some extent the symptoms. Improper hygiene of the removable orthodontic appliances is sometimes associated with stomatitis appearance, which may sometimes be overinfected with Candida albicans (Shah \& Sandler, 2006). Headgear appliance was linked to facial and intraoral trauma, appearing accidentally during game, sleep or incorrect handling. Blum-Hareuveni reports a case of a 12 year old boy who presented an ocular trauma by the external headgear arm, during sleep. He developed an intraocular infection (endophthalmitis), the final outcome being severe, decreased visual acuity. The author observes that in 10 out of 11 cases (the ones identified in the medical literature till that point) the consequences were dramatic, visual acuity decreasing to hand movement perception or less (Blum-Hareuveni et al., 2004; Blum-Hareuveni et al., 2006). After several cases of trauma associated with headgear devices were reported, modifications of its design were made in order to prevent this severe possible complication. 


\subsection{Temporomandibular joint disorders}

Postorthodontically temoporomandibular disorders are usually part of the craniomandibular dysfunction, which includes beside joint modifications also muscle and dental impairments. By the current research knowledge, it isn't clearly elucidated the relation between temporomandibular alterations and orthodontic intervention, usually being found contradictory opinions, explication varying. Some sustain that, by the state of morphofunctional equilibrium present after orthodontic intervention, optimal conditions for this side effects prevention are created. Other believe that, because of the premature occlusal contacts present during therapy, there is a greater risk for this complication to appear (Bourzgui et al., 2010; Gebeile-Chauty et al. 2010).

Before starting orthodontic treatment every patient must be examined in order to detect previous temporomandibular disorders and identify high risk patients. Aspects like inflammatory bone and muscular disorders (reumathoid arthritis), head and neck trauma, chronic head pain or high stress level must be taken into account. If signs and symptoms of temporomandibular disorders are present reaching a diagnosis is mandatory and also establishing its degree of severity. It isn't recommended to start an orthodontic therapy if the patient presents acute or severe signs of pain belonging to the temporomandibular disfunction. If severe modifications are observed during treatment, depending on case's particularities, it might be decided the correction of the abnormal occlusal contacts, referral to an orthopedic surgeon, or even treatment discontinuing. For patient who presented signs of temporomandibular disorder after active orthodontic treatment phase, it is recommended to take the necessary measures in order to prevent the relapse, the maintenance of a good morpho-functional equilibrium being essential. In some cases mouth guards as retention device may help in reducing the symptoms and facilitate healing (Graber et al., 2004).

\subsection{Allergic reactions}

One hypothetical reaction linked to the orthodontic treatment is the allergic one. Hypersensitivity reactions can occur associated to the well known allergens like nickel, cobalt, chromium, latex and polymers. The most frequent form is the contact dermatitis of the face and neck, but lesions can appear also on the oral mucosa and gingiva, and rarely even systemic reactions may occur.

Nickel allergies are the most frequent ones in the industrialized countries, manifesting usually as a type IV hypersensitivity reaction. Orthodontic devices contain approximately $8 \%$ nickel and the nickel-titanium alloy near 70\% nickel (Leite \& Bell, 2004). The allergic signs may vary from small rash on skin or mucosa, to generalized dermatitis. In high severity cases the manifestations may lead to discontinuation of the orthodontic treatment.

Another allergen taken into consideration when orthodontic treatment is performed is latex (from medical gloves, elastomeric ligatures, elastic chain, rubber dam etc). Prevalence of latex related allergies is reported as being lower than $1 \%$ in the general population, but greater than 5\% among dental professionals (Leite, 2004). Associated to it, types I and IV hypersensitivity reactions may appear, the most severe one, type I, being life threatening. In order to ensure a safe medical treatment it is important to identify allergic patients before starting the intervention. Higher risk present people with a history of complex or repeated surgical interventions (prolonged contact with rubber drains and tubes), those with spina 
bifida, and of course those who reported presence of itching and redness from contact to rubber objects and having allergies or contact dermatitis. A definitive diagnosis is established by combining the anamnestic data with the clinical data and hipersensibility tests. When allergic reaction to latex is identified, alternative latex-free devices should be used, and it is also recommended to avoid nickel-based components (Kolokitha, 2008).

\subsection{Infective endocarditis}

Infective endocarditis is rarely associated with the orthodontic interventions, but if it does, it can present severe complications that can be life threatening. The American Heart Association recommends prophylactic methods in order to prevent infectious endocarditis appearance if the patient presents prosthetic cardiac valve, previous infective endocarditis, congenital heart disease and cardiac transplantation with cardiac valvulopathy. The prophylaxis is mainly indicated in dental procedures that belong to oral and maxillofacial surgery, endodontics and periodontics, routinely in orthodontics being no need to implement it. Prophylactique therapy may be indicated in some particular orthodontic phases, where bleeding during interventions occur (e.g., teeth extraction, mini-implant placement used for anchorage control, interventions of orthognathic surgery and sometimes during placement and removal of orthodontic bands) (Wilson et al., 2007).

\section{Applications of the risk management principles within orthodontics}

Orthodontic treatment is a complex medical intervention, carried out over a long period of time, during which risks (seen as unplanned events) may materialize as complications. Their presence is linked to several factors like orthodontic technique, medical knowledge in this field, but also to patient's individual particularities (e.g., general and oral health). The outcome can include one or several side effects, generally, but not always, presenting low severity, appeared after initiation of orthodontic therapy or by aggravating some previous conditions. In order to ensure a high quality of the medical care, from the treatment planning phase, the risks must be considered, evaluated and communicated to the patient. This conduct promotes an optimal treatment period with lower risk of disagreements that may lead to malpractice complaint and even lawsuits.

One method for risks assessment may be to follow the methodology described in Risk Management, using the risk matrix (Table 6). This approach includes proactive management items (measures for avoiding and preventing the risk), as well as reactive elements (actions taken for minimizing damage after occurrence of the adverse effect). The use of risk management plan can't guarantee a health care intervention without side effects but, by controlling risks, it may considerably decrease the associated complications, ensuring a better prognosis.

At first it is necessary to identify the risks that are associated with the medical intervention that is going to be applied. By the current medical knowledge there are a great number of complications that are hypothetically linked to the orthodontic treatment. Their occurrence depends on numerous factors, from orthodontic technique (e.g., appliance type) to patient related variables (e.g., oral hygiene habits). These must be considered even from the start because it might influence treatment's objectives, phases and sometimes may even postpone the medical intervention. To identify the risks, it may be helpful for the orthodontist to ask himself the basics question "what may appear? why? how? when?". 


\section{RISK MANAGEMENT}

\begin{tabular}{ll}
\hline 1. & Risks identification \\
& • what may appear? why? how? when? \\
\hline 2. & Risks assessment $\rightarrow$ RISK MATRIX \\
& - value for probability (measures the extent to which risk can \\
& $\quad$ become real) \\
& - value for impact (measures the effect of a particular risk on the \\
& - outcome quality) \\
\hline 3. & Risk response planning \\
& - risk avoidance \\
- risk mitigation \\
- risk acceptance \\
- risk transfer
\end{tabular}

Table 6. Risk management phases.

After identifying the risks, the next step is their assessment. The identified risks are analyzed by the probability of appearance (e.g., likelihood; almost certain; likely; possible; unlikely; rare) and impact on the quality of healthcare intervention (e.g., severe; major; moderate; minor; insignificant) in conjunction. An ergonomic method to do this is to give scores to the items investigated and introduce the identified risks in a $2 \times 2$ table, this being known as a risk matrix analysis. For example, risk of severe root resorption can be differently assessed depending on case particularities. Generally, it is evaluated as being unlikely to appear, but if it does, it can have a major impact on tooth prognosis. But if, before beginning the orthodontic treatment, there can be detected signs of idiopathic root resorption, the probability of occurrence increases, transforming this risk into a priority issue, needed to be carefully considered when treatment plan is developed.

After that, the risk response is planned for those complications which, corresponding to the previous analysis, present the best chances to negatively influence the treatment outcome. In risk management there are described several techniques that can be applied individual or in conjunction (Piney, 2002). By risk avoidance there are addressed the measurements taken into consideration in order to minimize the situational risk as much as possible. For example in a high risk root resorption case, if it is possible, the treatment objectives should be minimized so treatment duration delivered by the orthodontist will be as short as possible and these means do not favor the side effects appearance. Risk mitigation refers to the actions taken in order to reduce the probability or the impact of the risk event. This type of measure can be integrated to the primary, secondary or tertiary prevention methods described for many pathological medical aspects (Ionescu et al., 2008). For example, in orthodontics there are described various procedures for minimizing enamel demineralization associated with bad oral hygiene habits, from motivating the patient and parents to indicating auxiliary devices (single-tuft brushes, oral irrigators) and fluoridebased products. Risk acceptance suggests the decision to accept the possibility of the event appearance. Acceptance can be passive, when the impact presents a minor impact on the outcome. In orthodontics this can be seen in the acceptance of minor root resorption process, a side effect present with a high frequency after this type of medical interventions, but with 
insignificant impact on outcome quality. Acceptance can be active; this means that, if the risks occur, the planned methods to minimize its consequences must be implemented. This is the case of infection risk, present in any medical surgical act (e.g., tooth extraction for orthodontic purposes, mini-implants placement, orthognathic surgery phases). Usually, it presents low frequency, but if it occurs, prompt response measurements must be taken. Risk transfer implies a $3^{\text {rd }}$ part that will bear partially or totally the risks if they appear. This type of risk response can be seen in contemporary medical field by the usage of informed consent. Patients are informed about the possible risks and complications of the medical intervention, by signing the informed consent, which certifies the understanding of the aspects mentioned and assume the possibility of side effects occurrence.

\section{Conclusions}

In conclusion, the risks associated with orthodontic treatment are a reality, complications being a result of a multifactorial process, including aspects related to patient, orthodontist and the technical features of orthodontic appliances and procedures. These can be prevented or limited through identification and implementation of best treatment alternative for each individual case. Patient's compliance is an important factor that can contribute to a high standard outcome, with minimum side effects.

\section{References}

Ackerman, M. (2004). Evidence-based orthodontics for the 21st century. Journal of the American Dental Association, Vol.135, No.2, pp. 162-167, ISSN 0002-8177

Al Maaitah, E.F., Adeyemi, A.A., Higham, S.M., Pender, N. \& Harrison, J.E. (2011). Factors affecting demineralization during orthodontic treatment: a post-hoc analysis of RCT recruits. American Journal of Orthodontics and Dentofacial Orthopedics, Vol.139, No.2, pp. 181-191, ISSN 0889-5406

Apajalahti, S. \& Peltola, J.S. (2007). Apical root resorption after orthodontic treatment - a retrospective study. European Journal of Orthodontics, Vol.29, No.4, pp.408-412, ISSN 0141-5387

Artun, J., Van 't Hullenaar, R., Doppel, D. \& Kuijpers-Jagtman, A.M. (2009). Identification of orthodontic patients at risk of severe apical root resorption. American Journal of Orthodontics and Dentofacial Orthopedics, Vol.135, No.4, pp. 448-455, ISSN 0889-5406

Atai, Z. \& Atai, M. (2007). Side Effects and Complications of Dental Materials on Oral Cavity. American Journal of Applied Sciences, Vol.4, No.11, pp. 946-949, ISSN 1554-3641

Bastos Lages, E.M., Drummond, A.F., Pretti, H., Costa, F.O., Lages, E.J., Gontijo, A.I., Miranda Cota, L.O. \& Brito, R.B. (2009). Association of functional gene polymorphism IL-1beta in patients with external apical root resorption. American Journal of Orthodontics and Dentofacial Orthopedics, Vol.136, No.4, pp. 542-546, ISSN 0889-5406

Bauss, O., Röhling, J., Sadat-Khonsari, R. \& Kiliaridis, S. (2008). Influence of orthodontic intrusion on pulpal vitality of previously traumatized maxillary permanent incisors. American Journal of Orthodontics and Dentofacial Orthopedics, Vol.134, No.1, pp. 12-17, ISSN 0889-5406

Benson, P.E., Parkin, N., Millett, D.T., Dyer, F., Vine, S. \& Shah, A. (2004). Fluorides for the prevention of white spots on teeth during fixed brace treatment. Cochrane Database of Systematic Reviews, No.3, CD003809. DOI: 10.1002/14651858.CD003809 
Bentahar, Z., Bourzgui, F., Zertoubi, M., EL Adioui- Joundy, S. \& Morgan, G. (2005). Dégradation électrochimique des matériaux métalliques utilisés en orthodontie. International Orthodontics, Vol. 3, No.5, pp. 5-17, ISSN 1761-7227

Blum-Hareuveni, T., Rehany, U. \& Rumelt, S. (2004). Blinding endophthalmitis from orthodontic headgear. New England Journal of Medicine, Vol.351, No.26, pp.27742775, ISSN 0028-4793

Blum-Hareuveni, T., Rehany, U. \& Rumelt, S. (2006). Devastating endophthalmitis following penetrating ocular injury during night sleep from orthodontic headgear: case report and literature review. Graefes Archive for Clinical and Experimental Ophthalmology, Vol.244, No.2, pp.253-258, ISSN 0721-832X

Bourzgui, F., Sebbar, M., Nadour, A. \& Hamza, M. (2010). Prevalence of temporomandibular dysfunction in orthodontic treatment. International Orthodontics, Vol.8, No.4, pp. 386-398, ISSN 1761-7227

Brezniak, N. \& Wasserstein, A. (2002). Orthodontically Induced Inflammatory Root Resorption. Part I: The Basic Science Aspects. Angle Orthodontist, Vol.72, No.2, pp. 175-179, ISSN 0003-3219

Chapman, J.A., Roberts, W.E., Eckert, G.J., Kula, K.S. \& González-Cabezas, C. (2010). Risk factors for incidence and severity of white spot lesions during treatment with fixed orthodontic appliances. American Journal of Orthodontics and Dentofacial Orthopedics, Vol.138, No.2, pp. 188-194, ISSN 0889-5406

Chaturvedi, T.P. \& Upadhayay, S.N. (2010). An overview of orthodontic material degradation in oral cavity. Indian Journal of Dental Research, Vol.21, No.2, pp. 275284, ISSN 0970-9290

Daniels, A.S., Seacat, J.D. \& Inglehart, M.R. (2009). Orthodontic treatment motivation and cooperation: a cross-sectional analysis of adolescent patients' and parents' responses. American Journal of Orthodontics and Dentofacial Orthopedics, Vol.136, No.6, pp. 780-787, ISSN 0889-5406

DiBiase, A. (2002). The timing of orthodontic treatment. Dental Update, Vol.29, No.9, pp. 434441, ISSN 0305-5000

Ellis, P.E. \& Benson, P.E. (2002). Potential Hazards of Orthodontic Treatment - What Your Patient Should Know. Dental Update, Vol.29, No.10, pp. 492-496, ISSN 0305-5000

Faltermeier, A., Rosentritt, M., Reicheneder, C. \& Behr, M. (2008). Discolouration of orthodontic adhesives caused by food dyes and ultraviolet light. European Journal of Orthodontics, Vol.30, No.1, pp. 89-93, ISSN 0141-5387

Fjeld, M. \& Øgaard, B. (2006). Scanning electron microscopic evaluation of enamel surfaces exposed to 3 orthodontic bonding systems. American Journal of Orthodontics and Dentofacial Orthopedics, Vol.130, No.5, pp. 575-581, ISSN 0889-5406

Gebeile-Chauty, S., Robin, O., Messaoudi, Y. \& Aknin, J.J. (2010). Can orthodontic treatment generate temporomandibular disorders and pain? A review. L'Orthodontie Francaise, Vol.81, No.1, pp.85-93, ISSN 0078-6608

Graber, T., Eliades, T. \& Athanasiou, A.E. (2004). Risk Management in Orthodontics: Expers' Guide to Malpractice, Quintessence Publishing Co, Inc, ISBN 0-86715-431-4, Chicago

Hosein, I., Sherriff, M. \& Ireland, A.J. (2004). Enamel loss during bonding, debonding, and cleanup with use of a self-etching primer. American Journal of Orthodontics and Dentofacial Orthopedics, Vol.126, No.6, pp. 717-724, ISSN 0889-5406 
Iglesias-Linares, A., Yáñez-Vico, R.M., Solano-Reina, E., Torres-Lagares, D. \& González Moles, M.A. (2010). Influence of bisphosphonates in orthodontic therapy: Systematic review. Journal of Dentistry, Vol.38, No.8, pp. 603-611, ISSN 0300-5712

Ionescu, E., Teodorescu, E., Badarau, A., Grigore, R. \& Popa, M. (2008). Prevention perspective in orthodontics and dento-facial orthopedics. Journal of Medicine and Life, Vol.1, No.4, pp.397-402, ISSN 1884-122x

Kalkwarf, K.L., Krejci, R.F. \& Pao, Y.C. (1986). Effect of apical root resorption on periodontal support. Journal of Prosthetic Dentistry. Vol.56, No.3, pp. 317-319, ISSN 0022-3913

Karamouzos, A., Athanasiou, A.E., Papadopoulos, M.A.\& Kolokithas, G. (2010). Tooth-color assessment after orthodontic treatment: a prospective clinical trial. American Journal of Orthodontics and Dentofacial Orthopedics, Vol.138, No.5, pp. 537.e1-8, ISSN 10976752

Kolokitha, O.E. \& Chatzistavrou, E. (2008). Allergic reactions to nickel-containing orthodontic appliances: clinical signs and treatment alternatives. World Journal of Orthodontics, Vol.9, No.4, pp.399-406, ISSN 1530-5678

Kouraki, E., Bissada, N.F., Palomo, J.M., Ficara, A.J. (2005). Gingival enlargement and resolution during and after orthodontic treatment. New York State Dental Journal, Vol.71, No.4, pp. 34-37, ISSN 0028-7571

Klukowska, M., Bader, A., Erbe, C., Bellamy, P., White, D.J., Anastasia, M.K. \& Wehrbein, H. (2011). Plaque levels of patients with fixed orthodontic appliances measured by digital plaque image analysis. American Journal of Orthodontics and Dentofacial Orthopedics, Vol.139, No.5, pp. 463-470, ISSN 1097-6752

KSV Instruments. (2008). Operating Manual for Contact Angle and Surface Tension Determination ( $2^{\text {nd }}$ edition), Helsinki

Lau, P.Y. \& Wong, R.W.K. (2006). Risks and complications in orthodontic treatment. Hong Kong Dental Journal, Vol.3, No.1, pp. 15-22, ISSN 1727-2300

Leite, L.P. \& Bell R.A. (2004). Adverse Hypersensitivity Reactions in Orthodontics. Seminars in Orthodontics, Vol.10, No. 4, pp. 240-243, ISSN 1073-8746

Lill, D.J., Lindauer, S.J., Tüfekçi, E. \& Shroff, B. (2008). Importance of pumice prophylaxis for bonding with self-etch primer. American Journal of Orthodontics and Dentofacial Orthopedics, Vol.133, No.3, pp. 423-426, ISSN 0889-5406

Linge, L. \& Linge B.O. (1991). Patient Characteristics and treatment variables associated with apical root resorption during orthodontic treatment. American Journal of Orthodontics and Dentofacial Orthopedics, Vol.99, No.1, pp. 35-43, ISSN, ISSN 08895406

Lopatiene, K. \& Dumbravaite, A. (2008). Risk factors of root resorption after orthodontic treatment. Stomatologija, Baltic Dental and Maxillofacial Journal, Vol.10, No.3, pp. 8995, ISSN 1392-8589

Øgaard, B. \& Fjeld, M. (2010). The Enamel Surface and Bonding in Orthodontics. Seminars in Orthodontics, Vol.16, No.1, pp. 37-48, ISSN 1073-8746

Piney, Crispin. (2003). Risk response planning: selecting the right strategy. Proceedings of Fifth European Project Management Conference, Cannes, France, June 2002

Preoteasa, C.T., Ionescu, E., Preoteasa, E., Comes, C.A., Buzea, M.C. \& Grămescu, A. (2009). Orthodontically induced root resorption correlated with morphological characteristics. Romanian Journal of Morphology and Embryology, Vol.50, No.2, pp. 257-262, ISSN 1220-0522 
Preoteasa, C.T. \& Ionescu, E. (2011). Link between skeletal relations and root resorption in orthodontic patients. International Journal of Medical Dentistry, Vol.1, No.3, pp. 267271, ISSN 2066-6063

Preoteasa, C.T., Ionescu, E., Didilescu, A.C., Melescanu-Imre, M., Bencze, M.A. \& Preoteasa, E. (2011a) Undesirable dental hard tissue effects hypothetically linked to orthodontics - a microscopic study. Romanian Journal of Morphology and Embryology, Vol.52, No.3, pp. 937-941, ISSN 1220-0522

Preoteasa, C.T., Nabil Sultan, A., Popa, L., Ionescu, E., Iosif, L., Ghica, M.V. \& Preoteasa, E. (2011b). Wettability of some dental materials. Optoelectronics And Advanced Materials - Rapid Communications, Vol.5, No.8, pp. 874-878,ISSN 1842-6573

Segal, G.R., Schiffman, P.H.\& Tuncay, O.C. (2004). Meta analysis of the treatment-related factors of external apical root resorption. Orthodontics and Craniofacial Research, Vol.7, No.2, pp. 71-78, ISSN 1601-6335

Shah, A.A. \& Sandler, J. (2006). Limiting factors in orthodontic treatment: 1. Factors related to patient, operator and orthodontic appliances. Dental Update, Vol.33, No.1, pp. 4344, 46-48, 51-52, ISSN 0305-5000

Shungin, D., Olsson, A.I. \& Persson, M. (2010). Orthodontic treatment-related white spot lesions: a 14-year prospective quantitative follow-up, including bonding material assessment. American Journal of Orthodontics and Dentofacial Orthopedics, Vol.138, No.2, pp. 1-8, ISSN 1097-6752

Smale, I., Artun, J., Behbehani, F., Doppel, D., van't Hof, M. \& Kuijpers-Jagtman, A.M. (2005). Apical root resorption 6 months after initiation of fixed orthodontic appliance therapy. American Journal of Orthodontics and Dentofacial Orthopedics, Vol.128, No.1, pp. 57-67, ISSN 0889-5406

Viazis, A.D., DeLong, R., Bevis, R.R., Rudney, J.D.\& Pintado, M.R. (1990). Enamel abrasion from ceramic orthodontic brackets under an artificial oral environment. American Journal of Orthodontics and Dentofacial Orthopedics, Vol.98, No. 2, pp. 103-109, ISSN 0889-5406

Vizitiu, T. C.\& Ionescu, E. (2010). Microbiological changes in orthodontically treated patients. Therapeutics, Pharmacology and Clinical Toxicology, Vol.14, No.4, pp. 283286, ISSN 1583-0012

Weltman, B., Vig, K.W., Fields, H.W., Shanker, S.\& Kaizar, E.E. (2010) Root resorption associated with orthodontic tooth movement: A Systematic Review American Journal of Orthodontics and Dentofacial Orthopedics, Vol.137, No.4, pp. 462-476, ISSN 0889-5406

Wilson, W., Taubert, K. A., Gewitz, M., Lockhart, P. B., Baddour, L. M., Levison, M., Bolger, A., Cabell, C. H., Takahashi, M., Baltimore, R. S., Newburger, J. W., Strom, B. L., Tani, L. Y., Gerber, M., Bonow, R. O., Pallasch, T., Shulman, S. T., Rowley, A. H., Burns, J. C., Ferrieri, P., Gardner, T., Goff, D. \& Durack, D. T. (2007). Prevention of infective endocarditis: guidelines from the American Heart Association, Journal of the American Dental Association, Vol.138, No.6, pp. 739-745,747-760, ISSN 0002-8177

World Health Organization. (1946). Preamble to the Constitution of the World Health Organization as adopted by the International Health Conference in 1946, In: Basic Documents, 24.08.2011, Available from: http://www.who.int/governance/eb/who_constitution_en.pdf 


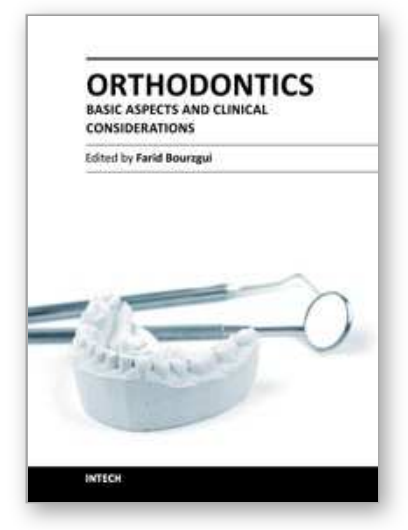

\author{
Orthodontics - Basic Aspects and Clinical Considerations \\ Edited by Prof. Farid Bourzgui
}

ISBN 978-953-51-0143-7

Hard cover, 446 pages

Publisher InTech

Published online 09, March, 2012

Published in print edition March, 2012

The book reflects the ideas of nineteen academic and research experts from different countries. The different sections of this book deal with epidemiological and preventive concepts, a demystification of cranio-mandibular dysfunction, clinical considerations and risk assessment of orthodontic treatment. It provides an overview of the state-of-the-art, outlines the experts' knowledge and their efforts to provide readers with quality content explaining new directions and emerging trends in Orthodontics. The book should be of great value to both orthodontic practitioners and to students in orthodontics, who will find learning resources in connection with their fields of study. This will help them acquire valid knowledge and excellent clinical skills.

\title{
How to reference
}

In order to correctly reference this scholarly work, feel free to copy and paste the following:

Cristina Teodora Preoteasa, Ecaterina Ionescu and Elena Preoteasa (2012). Risks and Complications Associated with Orthodontic Treatment, Orthodontics - Basic Aspects and Clinical Considerations, Prof. Farid Bourzgui (Ed.), ISBN: 978-953-51-0143-7, InTech, Available from:

http://www.intechopen.com/books/orthodontics-basic-aspects-and-clinical-considerations/risks-andcomplications-associated-with-orthodontic-treatment

\section{INTECH}

open science | open minds

\section{InTech Europe}

University Campus STeP Ri

Slavka Krautzeka 83/A

51000 Rijeka, Croatia

Phone: +385 (51) 770447

Fax: +385 (51) 686166

www.intechopen.com

\section{InTech China}

Unit 405, Office Block, Hotel Equatorial Shanghai

No.65, Yan An Road (West), Shanghai, 200040, China

中国上海市延安西路65号上海国际贵都大饭店办公楼 405 单元

Phone: +86-21-62489820

Fax: $+86-21-62489821$ 
(C) 2012 The Author(s). Licensee IntechOpen. This is an open access article distributed under the terms of the Creative Commons Attribution 3.0 License, which permits unrestricted use, distribution, and reproduction in any medium, provided the original work is properly cited. 